Supplement of The Cryosphere, 11, 517-529, 2017

http://www.the-cryosphere.net/11/517/2017/

doi:10.5194/tc-11-517-2017-supplement

(C) Author(s) 2017. CC Attribution 3.0 License.

(c) (i)

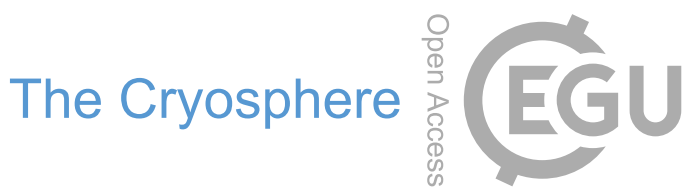

Supplement of

\title{
How much can we save? Impact of different emission scenarios on future snow cover in the Alps
}

Christoph Marty et al.

Correspondence to: Christoph Marty (marty@slf.ch)

The copyright of individual parts of the supplement might differ from the CC-BY 3.0 licence. 
Table S1: Root mean squared error (RSME) calculated for snow depths greater than $\mathbf{0 . 0 1} \mathbf{m}$ for selected stations in the Aare and Grisons catchment during the 13 years of the reference period.

\begin{tabular}{|c|c|c|c|c|c|c|c|c|c|c|c|c|c|c|}
\hline Stat & Altitude & 2000 & 2001 & 2002 & 2003 & 2004 & 2005 & 2006 & 2007 & 2008 & 2009 & 2010 & 2011 & 2012 \\
\hline Chur & $550 \mathrm{~m}$ & 0.04 & 0.03 & 0.03 & 0.03 & 0.03 & 0.03 & 0.03 & 0.06 & 0.03 & 0.03 & 0.03 & 0.03 & 0.03 \\
\hline Bern & $550 \mathrm{~m}$ & 0.09 & 0.04 & 0.08 & 0.05 & 0.06 & 0.06 & 0.08 & 0.08 & 0.03 & 0.08 & 0.08 & 0.09 & 0.05 \\
\hline Disentis & $1090 \mathrm{~m}$ & 0.18 & 0.17 & 0.18 & 0.18 & 0.16 & 0.17 & 0.18 & 0.19 & 0.17 & 0.17 & 0.18 & 0.15 & 0.18 \\
\hline Arosa & $1320 \mathrm{~m}$ & 0.42 & 0.41 & 0.41 & 0.44 & 0.42 & 0.42 & 0.43 & 0.47 & 0.43 & 0.43 & 0.44 & 0.40 & 0.44 \\
\hline Samedan & $1750 \mathrm{~m}$ & 0.31 & 0.29 & 0.31 & 0.31 & 0.29 & 0.31 & 0.32 & 0.31 & 0.31 & 0.30 & 0.30 & 0.26 & 0.33 \\
\hline Weissfluhjoch & $2540 \mathrm{~m}$ & 0.98 & 0.95 & 1.02 & 1.02 & 0.98 & 1.03 & 1.02 & 1.04 & 1.05 & 1.00 & 0.98 & 1.01 & 1.03 \\
\hline
\end{tabular}


Table S2: Mean number of snow days (snow depth at least $5 \mathrm{~cm}$ ) for the reference and the three future time periods based on the A2 scenario for 5 stations in the Aare region (above) and the Grisons region (below).

\begin{tabular}{llrrrr}
\hline Station & Elevation & Reference & 2035 & 2060 & 2085 \\
\hline Bern & $542 \mathrm{~m}$ & 40 & 13 & 5 & 0 \\
Interlaken & $568 \mathrm{~m}$ & 41 & 14 & 6 & 0 \\
Grindelwald & $1034 \mathrm{~m}$ & 101 & 72 & 37 & 14 \\
Adelboden & $1350 \mathrm{~m}$ & 139 & 107 & 75 & 35 \\
Mürren & $1650 \mathrm{~m}$ & 173 & 148 & 116 & 77 \\
& & & & & \\
\hline \multirow{2}{*}{ Chur } & $593 \mathrm{~m}$ & 39 & 14 & 5 & 0 \\
Disentis & $1130 \mathrm{~m}$ & 98 & 68 & 40 & 18 \\
Davos & $1560 \mathrm{~m}$ & 157 & 123 & 86 & 49 \\
Samedan & $1721 \mathrm{~m}$ & 165 & 139 & 101 & 61 \\
Weissfluhjoch & $2690 \mathrm{~m}$ & 254 & 228 & 197 & 163 \\
& & & & & \\
\hline
\end{tabular}



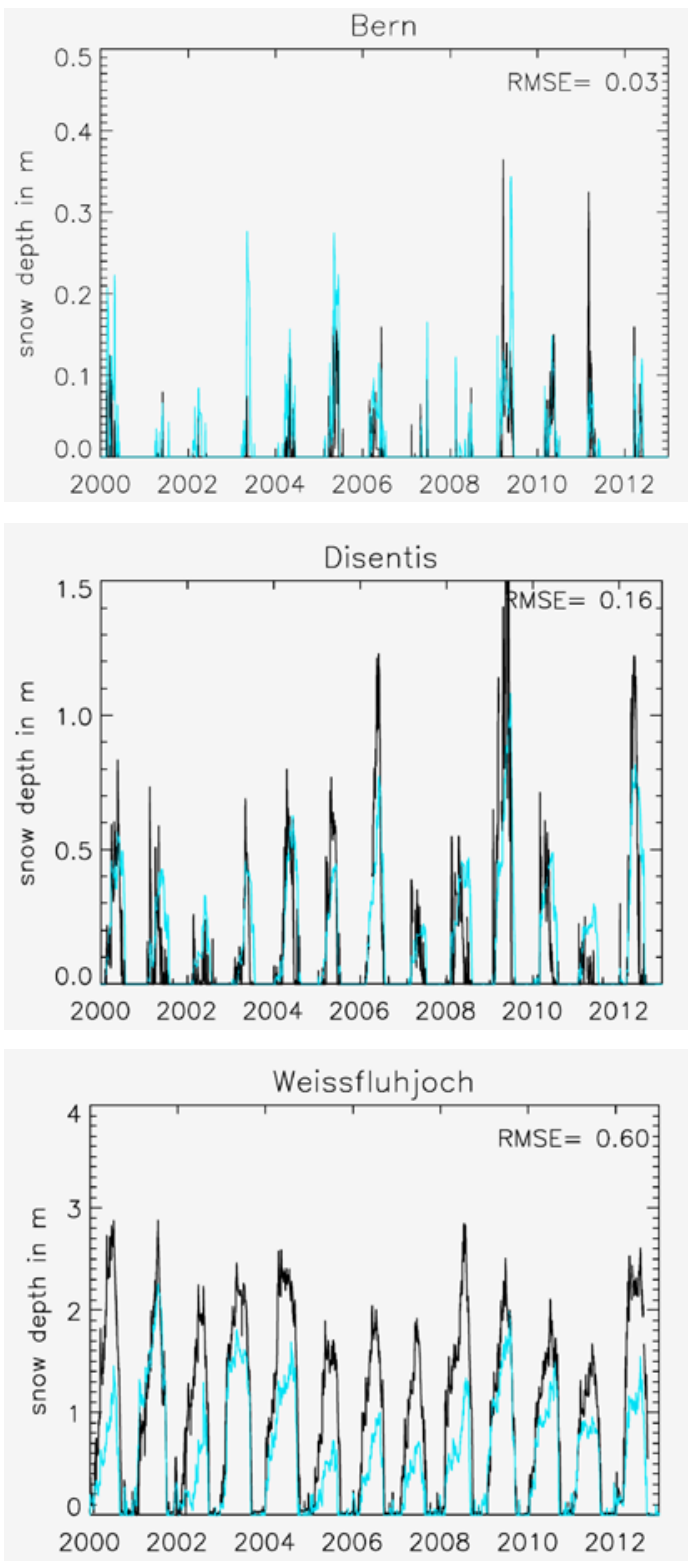

Figure S1: Measured (black) and simulated snow depth (grey) for Bern (542 m), Disentis (1190 m) and Weissfluhjoch (2540 m). Note: the scale of the $y$-axis is different for each station. 

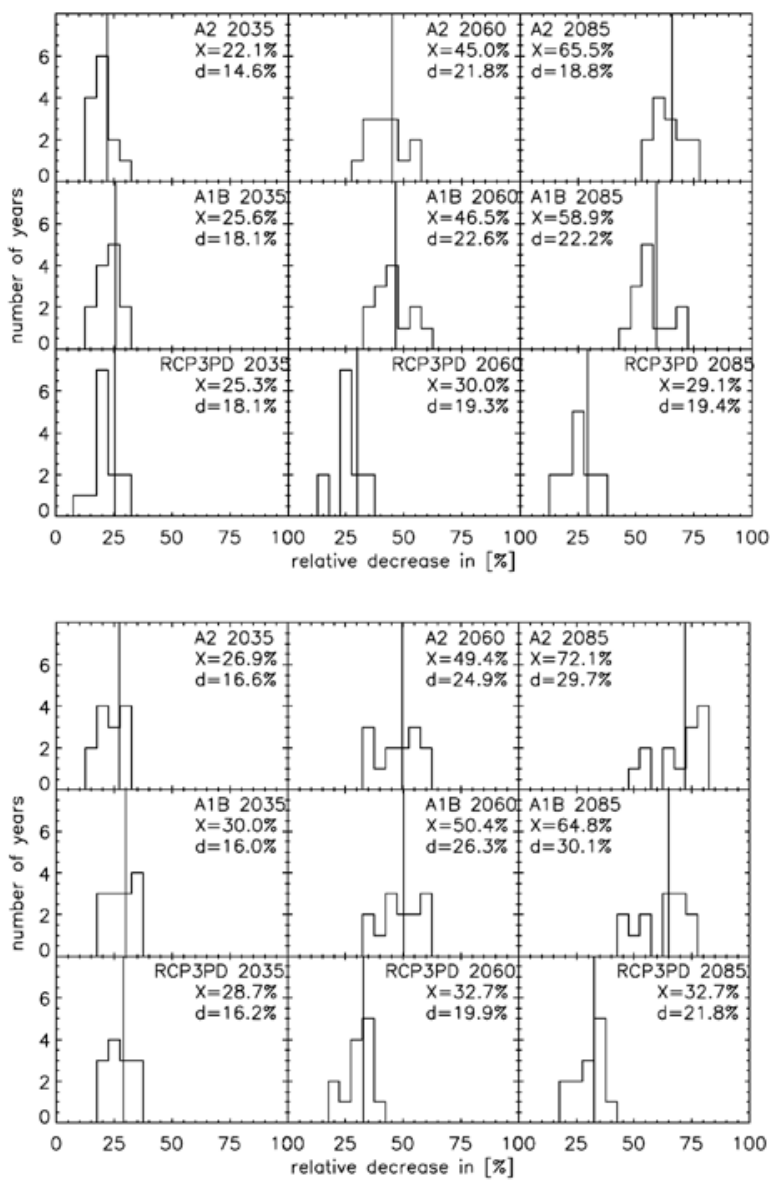

Figure S2: Distribution of the annual relative decreases of the snow depth for A2, A1B and RCP3PD and the three different future 5 time periods (2020-49, 2045-74, 2070-99) for Aare (top) and Grisons (bottom) based on the inter-annual variability of the reference period. The value $X$ corresponds to the spatial and temporal mean relative decrease in [\%], which is visualized in Figure 3 . The value d defines the difference between the highest and the lowest relative decrease within the scenario period. The number of the simulated years is $\mathrm{N}=13$. 

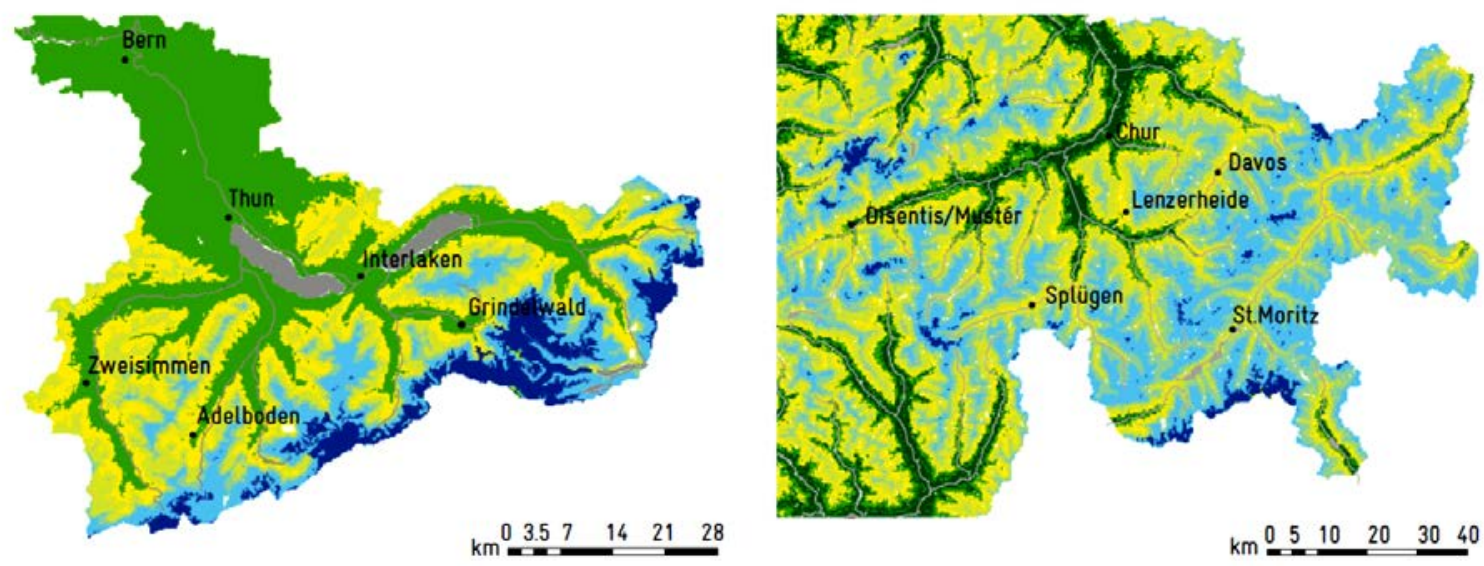

Relative decrease (\%)

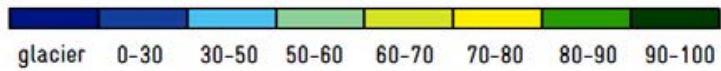

Figure S3: Relative decrease for February 1 snow depth during the last time period (2085) and the A1B scenario for the Aare region (left) and the Grisons region (right). 


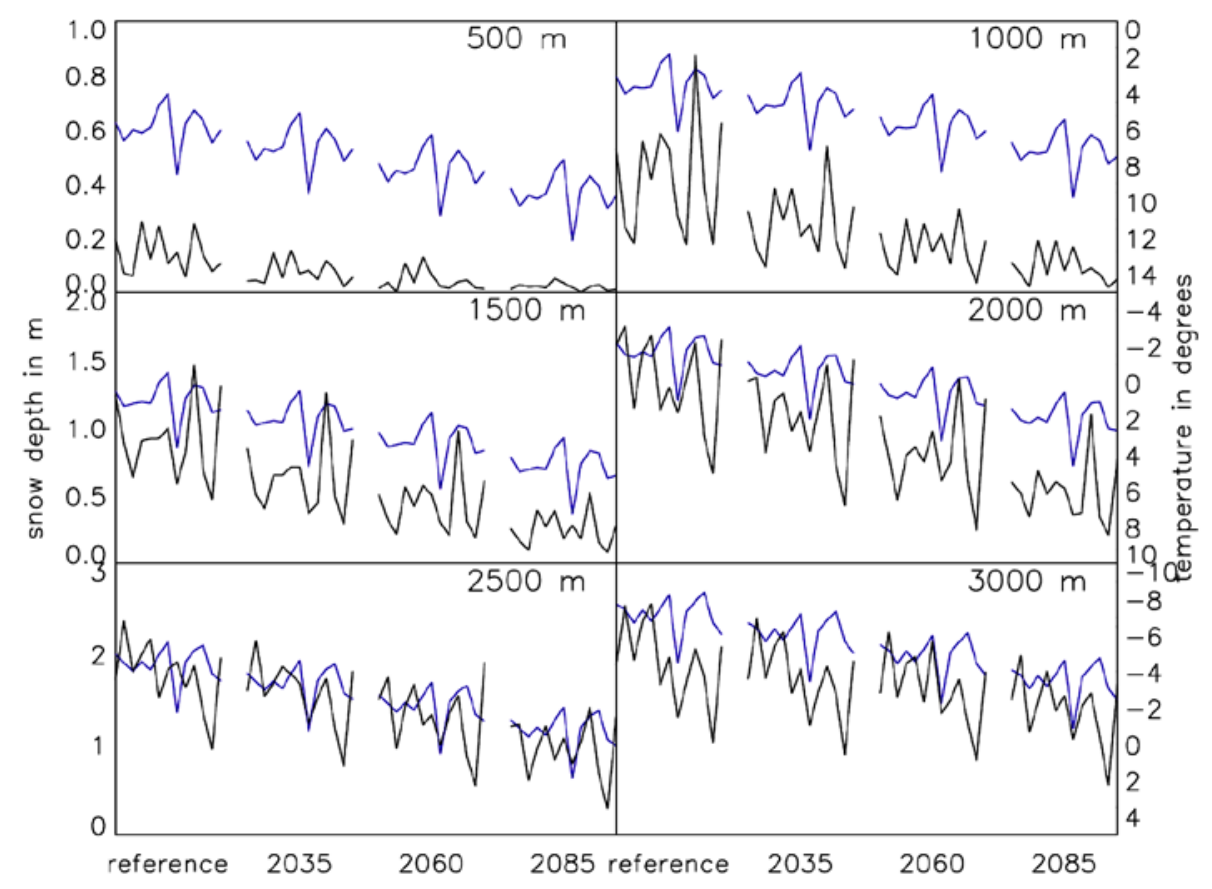

5 Figure S4: Current and future variability of maximum snow depth (solid line) and mean winter temperature (dashed line) from November to April for 6 elevation zones and the A2 scenario for the Aare region. Note, the scale of the $y$-axis changes with elevation. 


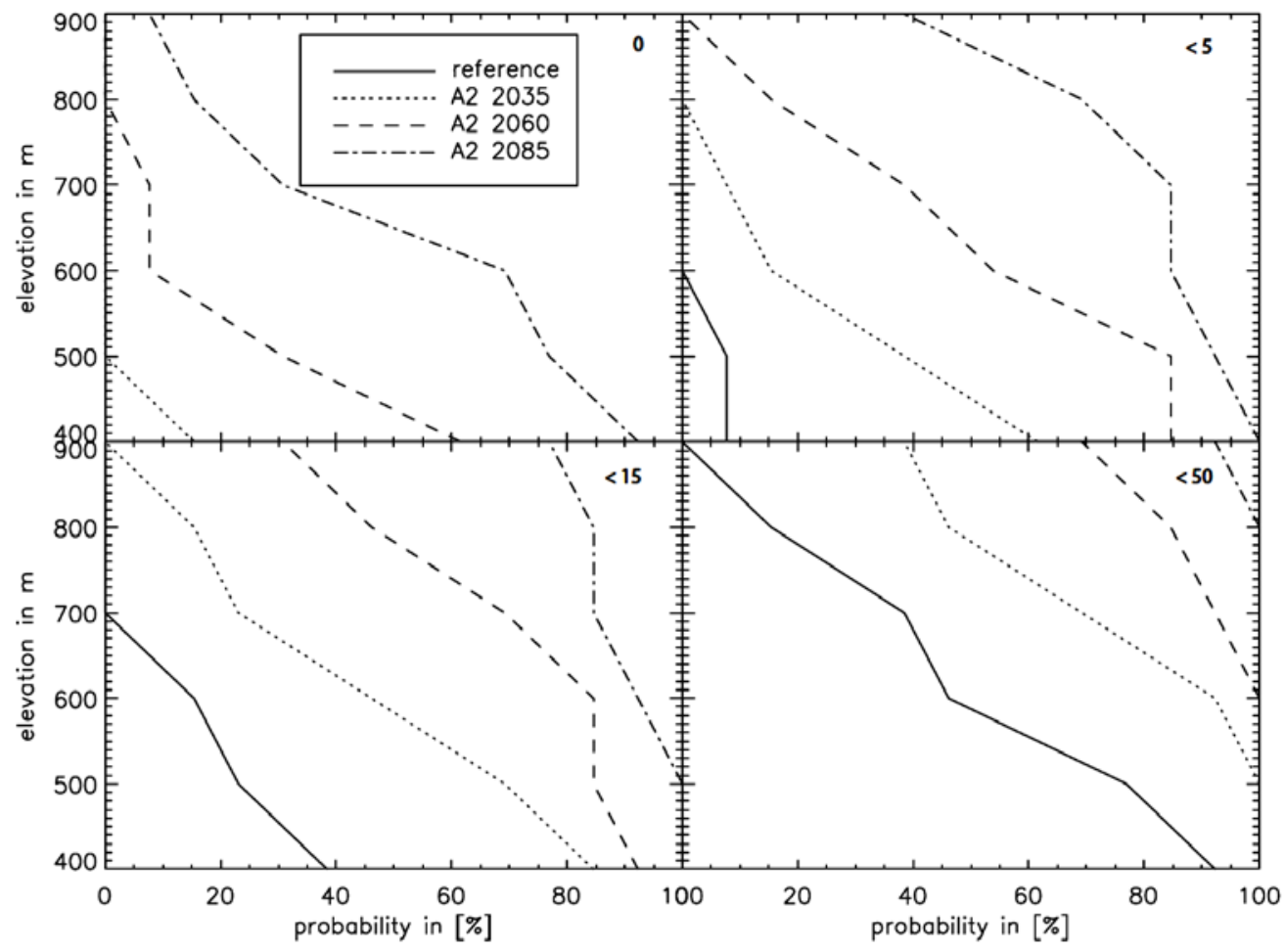

Figure S5: Probability of winter with 0 (upper left), less than 5 (upper right), less than 15 (lower left) and less than 50 (lower right) 5 snow days for Grisons. 

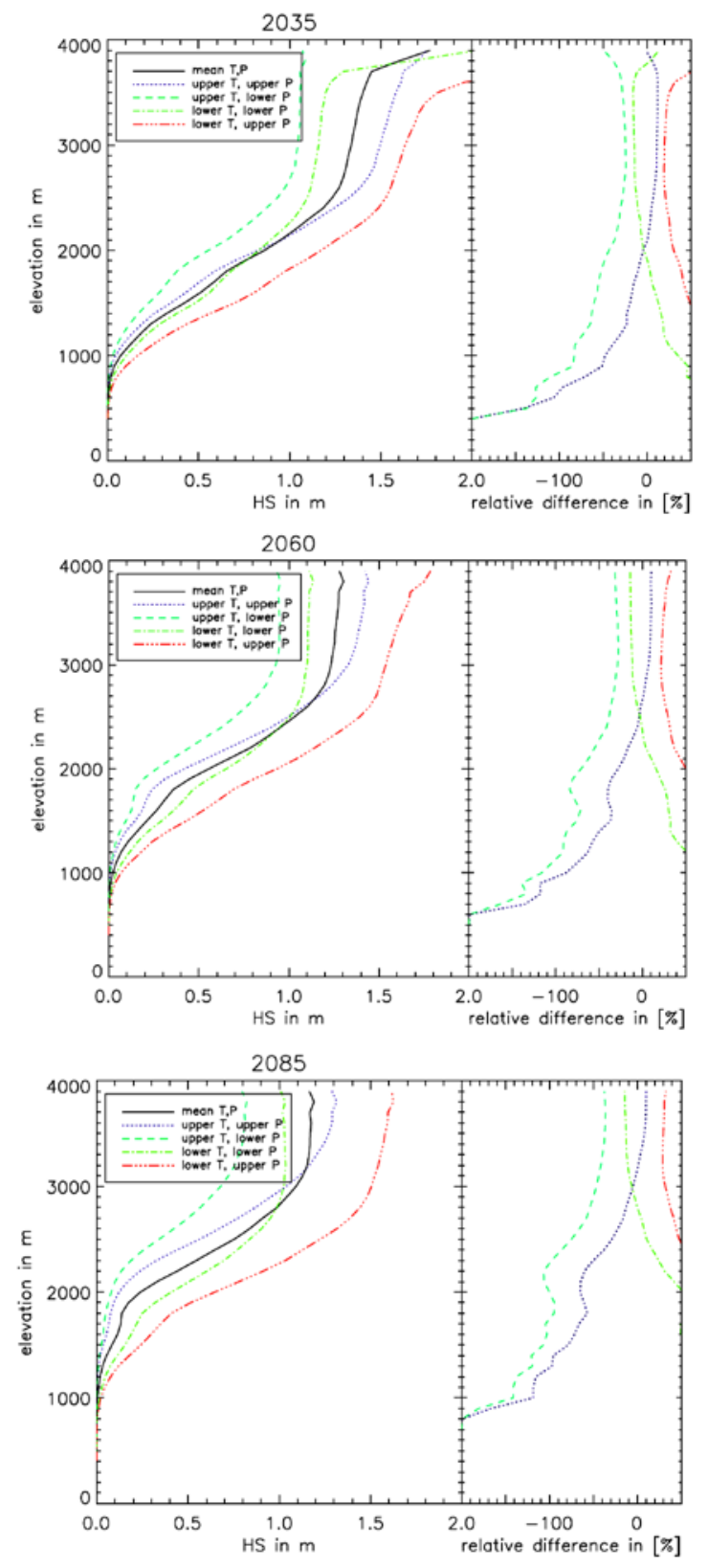
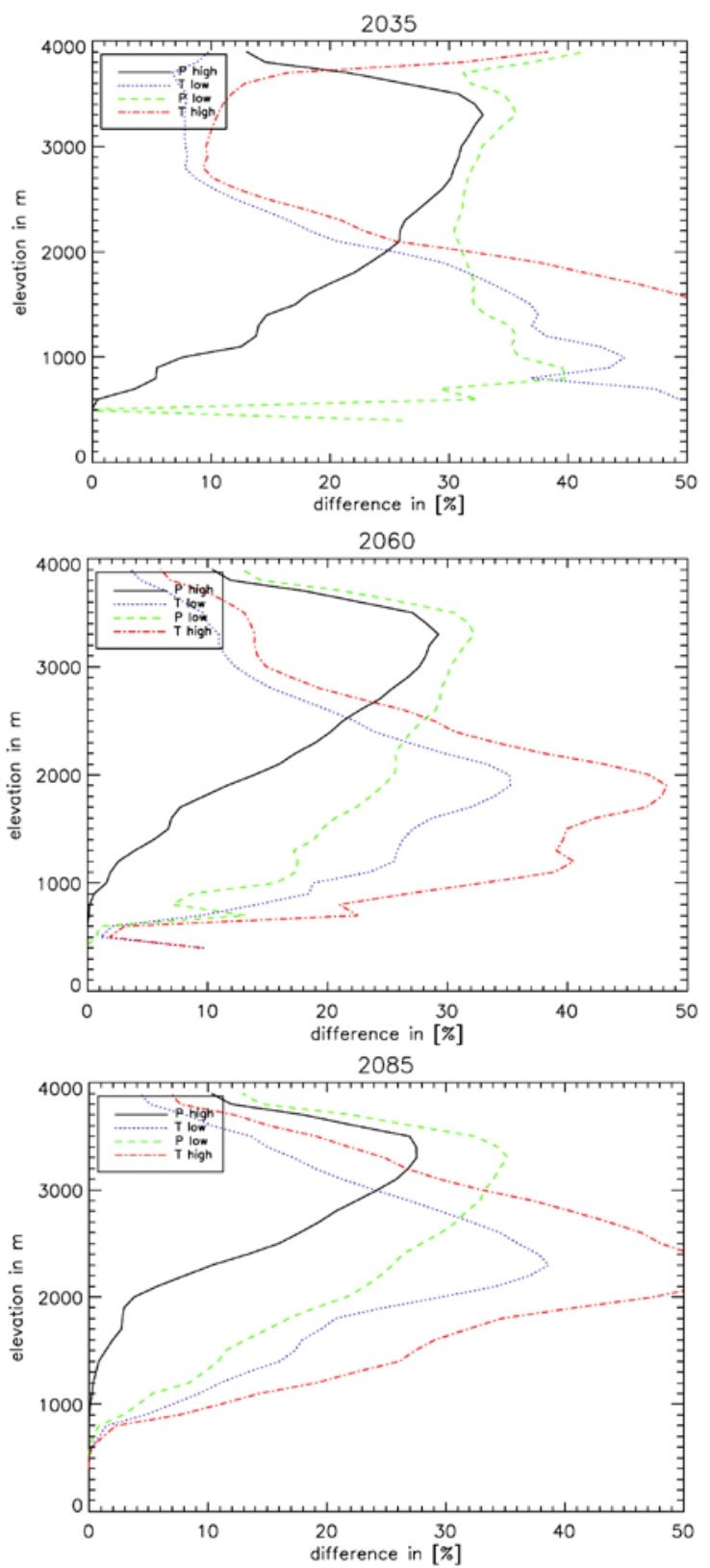

Figure S6: Elevation dependence of absolute snow depth for five possible T-P combinations (left) and decrease relative to the mean T, mean $\mathbf{P}$ configuration (left panels). Elevation dependence of the relative snow depth difference (\%) for four different 5 combinations T-P (right panels). "T high" means the difference of the upper $T$ - lower $T$ at the upper $P$ configuration. "P low" means the difference of the upper $P$ - lower $P$ at the lower T configuration. This is shown for 2035 (top), 2060 (middle) and 2085 (bottom) based on the $\mathrm{A} 2$ emission scenario in the Aare region. 